\title{
Food and Nutrient Intakes of Patients with Colorectal Cancer in Calicut District of Kerala
}

\author{
Aparna S Gopakumar ${ }^{1}$, Sudheena $\mathrm{K}^{2}$ \\ ${ }^{I}$ (Research Scholar, Department of Home Science, ST. Teresa's College, M G University, India) \\ ${ }^{2}$ (PG Student, Department of Home Science, Vimala College, Calicut University, India)
}

\begin{abstract}
Colorectal cancer, a multi factorial disease characterised by neoplasia of colon, rectum or vermiform appendix, is the third most common malignancy in the world. The worldwide incidence of colorectal cancer has increased rapidly in the past few decades and dietary habits have been considered as a major causative factor. The major objective of the study was to assess the food and nutrient intake of patients with colorectal cancer in Calicut District. The survey using interview schedule assessed the food and nutrient intake of colorectal cancer patients belonging to Calicut District of Northern Kerala. The study involved a sample of hundred newly diagnosed patients with colorectal cancer, belonging to the age group 30-55 years. The samples were selected by employing purposive random sampling from patients in the area of study. All the results were then analysed. The results showed that diets of the patients had some nutritional inadequacies. The RDA for intake of sugar, cereals, meat, pulses, vegetables, roots \& tubers, green leafy vegetable and milk were lesser than the normal requirements for an adult male and female subject. This may be due to the reduced food consumption of the subjects due to their illness and related complications.
\end{abstract}

Keywords :Cancer, Colorectal cancer, 24 hour recall, Recommended Dietary Allowance, Food and nutrient intake

\section{INTRODUCTION}

Cancer is a genetic disease, with two main characteristics of uncontrolled growth of cells in the human body and the availability of those cells to migrate from the original site and spread to distant sites. It is one of the leading causes of death in the world, particularly in developing countries.

Colorectal cancer is a multifactorial disease. CRC, less formally known as bowel cancer, is a cancer characterized by neoplasia of the colon, rectum or vermiform appendix. Most colon cancers are adeno carcinomas i.e., cancers originating from the epithelial cells lining the colon or rectum ${ }^{[1]}$. Symptoms of colorectal cancer typically include rectal bleeding and anemia which are sometimes associated with weight loss and changes in bowel habits.

Dietary habits have been considered as one of the major factors leading to the incidence of colon cancer ${ }^{[2]}$.However, etiology of colorectal cancer is relatively poorly understood, although diet is thought to play an important role in modifying cancer risk. Studies revealed that a diet that is high in cholesterol and far along with low in fibre drastically increased the risk of colorectal cancer ${ }^{[3]}$. High dietary fat intake is a risk factor for colon cancer development ${ }^{[4]}$. In addition heavy consumption of salted fish and pickled vegetables has been tied to higher colon cancer risk. People who regularly ate hefty servings of red or processed meat had an elevated colorectal cancer risk, as did people who got little fiber in their diet.

In Kerala, the highest incidence of colorectal cancer was found to be among the people of Malabar, where the diets are mainly rich in fats, fishes and red meats ${ }^{[5]}$.Though the dietary pattern found in Calicut District, a part of Malabar region varies substantially from other districts of Kerala, there is a lack of detailed research assessing the nutritional status of patients with colorectal cancer. Hence the quantitative assessment of the food and nutrient intake pattern of the people of Calicut also helps in assessing their nutritional status.

The present study entitled "Food and Nutrient Intakes of Patients with Colorectal Cancer in Calicut District of Kerala" highlights the food and dietary intake pattern of colorectal cancer patients thereby giving information about the adequacy of the diet taken by the patients. Since nutritional therapies are highly relevant in the treatment and management of colorectal cancer, the current study was done to provide useful data regarding the food and nutrient intake status of the colorectal cancer patients.

\subsection{Selection of samples and locale of the study}

\section{Methodology}

The study comprised a documentation of systematic investigation on a sample size of hundred patients with colorectal cancer, belonging to the age group 30-55 years, all hailing from Calicut District of Northern Kerala. The samples were chosen randomly from hospitals of Calicut. A purposive random sampling method was employed for the selection of samples for the study. 


\subsection{Assessment of the food and nutrient intake of the patients with colorectal cancer}

A diet survey provides information about dietary intake patterns of specific foods consumed and estimated nutrient intakes ${ }^{[6]}$. Internationally accepted tools based on earlier studies were selected for data collection.

24 hour recall method was employed in the study to assess the food and nutrient intake of the subjects. This method was selected because of the ease of administration, less time required and also due to good reliability. The actual food intakes of the individuals were recorded. A set of standardized cups suited to local conditions were used and information on the total cooked amount of each preparation was noted in terms of standardized cups ${ }^{[7]}$.

The mean food intakes of the subjects were calculated and nutritive value of food was computed using food composition table and compared with the RDA ${ }^{[8]}$. The results were then statistically analyzed. Percentage analysis, mean, standard deviation and z-test were the major statistical tools employed wherever necessary.

\section{Results And Discussion}

The study involved the selection of 100 colorectal cancer patients, of which 65 per cent were males and 35 per cent were females. The details regarding the personal characteristics of the subjects showed that 24 per cent of the male and 21 per cent of the female subjects belonged to the age group 30-45 years, whereas 41 per cent of the male subjects and 14 per cent of the female subjects belonged to the age group of 46-55 years.

\subsection{Food and nutrient intake of the subjects}

Nutritional decline is often accepted as a part of the natural history of cancer and its treatment. As many as 20 per cent of patients with cancer die from the effects of malnutrition rather than due to malignancy ${ }^{[9]}$.The subjects, who were diagnosed with colorectal cancer, were assessed for their food and nutrient intake, with the help of 24 hour recall history and then compared with RDA.

\subsubsection{Food intake of the subjects}

The food and nutrient intakes of the subjects was determined by 24 hour recall method to assess the quantity, quality and nutrients present in their diet. The quantity of each food item and the nutrients were compared with the RDA for adult man and woman (moderate worker) ${ }^{[7]}$.

\subsubsection{Food intake of the male subjects}

Details of food intake by the male subjects are given in table 1 .

Table 1 Food intake of the male subjects $(n=65)$

\begin{tabular}{|l|c|c|c|}
\hline \multicolumn{1}{|c|}{ Food groups } & $\begin{array}{c}\text { *RDA (moderate } \\
\text { worker) }\end{array}$ & $\begin{array}{c}\text { Mean food } \\
\text { intake }\end{array}$ & $\begin{array}{c}\text { Percentage of RDA } \\
\text { met }\end{array}$ \\
\hline Cereals & 450 & 240.61 & 53 \\
\hline Pulses & 90 & 33.53 & 37 \\
\hline Roots \& Tubers & 200 & 54.61 & 27 \\
\hline Green leafy vegetables & 100 & 24.15 & 32 \\
\hline Other vegetables & 200 & 64.69 & 95 \\
\hline Fruits & 100 & 94.61 & 46 \\
\hline Milk & 300 & 48.61 & 99 \\
\hline Meat & 90 & 38.76 & 57 \\
\hline Fats \& Oils & 30 & 29.69 & 17.15 \\
\hline Sugar & 30 & & \\
\hline * & & & \\
\hline
\end{tabular}

Data revealed that about 95 per cent of RDA of fruits was met. It was found that in diagnosed patients, the fruit intake was almost similar to their RDA. Fruits and vegetables are important in diet as they contain a good range of nutrients, including vitamins, minerals, antioxidants and fibre and give the body the tools to heal itself. Dietary pattern rich in fruits and vegetables have a protective effect against gastric and colorectal cancer whereas a positive association was seen in between cancer and dietary patterns rich in meats, animal fats and starchy foods ${ }^{[10]}$. After diagnosis the subjects consumed plenty of fruits due to the beneficial effects of fruits against cancer. The RDA for intake of sugar (57 per cent), cereals (53 per cent), meat (43 per cent), pulses (37 per cent), vegetables ( 32 per cent), roots $\&$ tubers ( 27 per cent), green leafy vegetable ( 24 per cent) and milk (16 per cent) were lesser than the normal requirements for an adult male subject. This may be due to the reduced food consumption of the subjects due to their illness and related complications. 
3.1.1.2. Food intake of the female subjects

Details of the food intake by female subjects are presented in table 2

Table 2 Food intake of the female subjects $(n=35)$

\begin{tabular}{|l|c|c|c|}
\hline \multicolumn{1}{|c|}{ Food groups } & *RDA (moderate worker) & Mean food intake & Percentage of RDA met \\
\hline Cereals & 330 & 274.5 & 83 \\
\hline Pulses & 75 & 39.71 & 53 \\
\hline Roots \& Tubers & 200 & 57.85 & 29 \\
\hline Green leafy vegetables & 100 & 25.71 & 26 \\
\hline Other vegetables & 200 & 86.28 & 43 \\
\hline Fruits & 100 & 97.42 & 97 \\
\hline Milk & 300 & 54.28 & 18 \\
\hline Meat & 75 & 30.85 & 41 \\
\hline Fats \& Oils & 25 & 9.71 & 39 \\
\hline Sugar & 30 & 14 & 47 \\
\end{tabular}

The table revealed that about 97 per cent of RDA of fruits was met. Fruits and vegetables consumption of female subjects were slightly higher than the male subjects. Vegetable, green leafy vegetable, milk and pulse consumption were found to be less when compared to the RDA.

\subsubsection{Nutrient intake of the subjects}

The mean nutrient intake of the subjects were calculated and compared with the RDA.

\subsubsection{Nutrient intake of the male subjects}

Details of the nutrient intake of the male subjects are given in table 3.

Table 3 Nutrient intake of male subjects $(n=65)$

\begin{tabular}{|l|l|l|l|l|}
\hline Nutrient & Mean & RDA $^{*}$ & z-value & Per cent of RDA met \\
\hline Energy & 1456.1 & 2730 & $49.611^{* *}$ & 53.34 \\
\hline Protein & 44.2 & 60 & $10.941^{* *}$ & 73.63 \\
\hline Fat & 20.9 & 30 & $9.914^{* *}$ & 69.6 \\
\hline Iron & 12.8 & 17 & $5.262^{* *}$ & 75.29 \\
\hline Calcium & 393.1 & 600 & $8.33^{* *}$ & 65.51 \\
\hline Thiamin & 1.0 & 1.4 & $7.836^{* *}$ & 69.41 \\
\hline Riboflavin & 0.9 & 1.4 & $9.502^{* *}$ & 65.62 \\
\hline Niacin & 13.1 & 18 & $9.845^{* *}$ & 72.79 \\
\hline Vitamin C & 122.9 & 40 & $8.147^{* *}$ & -107.21 \\
\hline Carotene & 1133.7 & 4800 & $15.309 * *$ & 23.62 \\
\hline Retinol & 74.3 & 600 & $44.64 * *$ & 12.38 \\
\hline * 8$]$ & & & \\
\hline
\end{tabular}

**significant at 0.01 levels

The data revealed that the intake of all the nutrients except Vitamin $\mathrm{C}$ was found to be lower than the RDA. The proximate principles of foods such as calorie, protein and fat intake were less among the male subjects when compared with the RDA. Energy intake met 53.34 per cent of the RDA. This reduced nutrient intake was found to be mainly due to the low food intake especially cereals, pulses, milk etc. by the subjects, which might be due to their lack of appetite and other problems related to their disease condition. Increased intake of vitamin $\mathrm{C}$ was seen among the patients because of the higher intake of fruits like oranges by the patients.

z-test was carried out for comparing the nutritive intake of the male subjects with RDA values. In the case of energy and all other nutrients $z$-value was found to be significant at 0.01 levels. Mean energy intake for the samples were found to be 1456.1, which was significantly lower than the RDA value followed by protein, fat, iron, calcium, B vitamins and vitamin $\mathrm{A}$ (beta-carotene and retinol). The vitamin $\mathrm{C}$ intake of the subjects was found to be higher than the RDA and the z-value 8.147 was significant at 0.01 levels. Fig. 1 represents the nutrient intake of male subjects. 


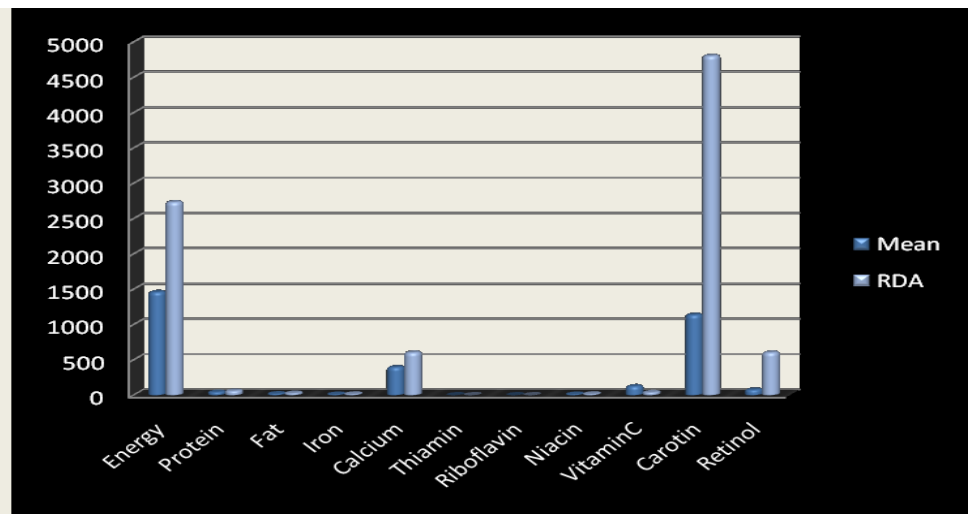

Figure 1 Nutrient intake of male subjects

\subsubsection{Nutrient intake of the female subjects}

The data regarding the nutrient intake of the female subjects revealed that the mean intakes of all the nutrients were low when compared to the RDA, except for vitamin C. The mean energy (1378.9) of the female subjects was found to be below the RDA. Iron intake met about 63.67 per cent whereas calcium intake met 60.96 per cent of the normal requirements.

z-test showed a significance of 0.01 for all the nutrients. Vitamin $\mathrm{C}$ intake was found to be three times higher than the RDA for female subjects. Vitamin $\mathrm{C}$, an antioxidant vitamin, is believed to find off cancer by enhancing the immune system and detoxifying compounds (responsible for causing cancer) in the liver. It also blocks the formation of nitrosamines in the digestive tract ${ }^{[11]}$.

Details regarding the nutrient intake of the female subjects are given in Table 4 and Fig. 2.

Table 4 Nutrient intake of female subjects $(n=35)$

\begin{tabular}{|c|c|c|c|c|}
\hline Nutrient & Mean & RDA $^{*}$ & z-value & Per cent of RDA met \\
\hline Energy & 1378.9 & 2230 & $23.94 * *$ & 61.83 \\
\hline Protein & 40 & 50 & $6.88^{* *}$ & 80.00 \\
\hline Fat & 21.1 & 25 & $4.22 * *$ & 84.36 \\
\hline Iron & 13.4 & 21 & $6.00 * *$ & 63.67 \\
\hline Calcium & 365.8 & 600 & $7.21 * *$ & 60.96 \\
\hline Thiamin & 0.8 & 1.1 & $7.38 * *$ & 74.09 \\
\hline Riboflavin & 0.8 & 1.3 & $9.08 * *$ & 59.8 \\
\hline Niacin & 11.5 & 14 & $5.42 * *$ & 82.21 \\
\hline Vitamin C & 124.6 & 40 & $5.46^{* * *}$ & -111.57 \\
\hline Carotene & 1406.5 & 4800 & $9.021 * *$ & 29.31 \\
\hline Retinol & 68.39 & 600 & $34.406 * *$ & 11.4 \\
\hline
\end{tabular}

**significant at 0.01 levels

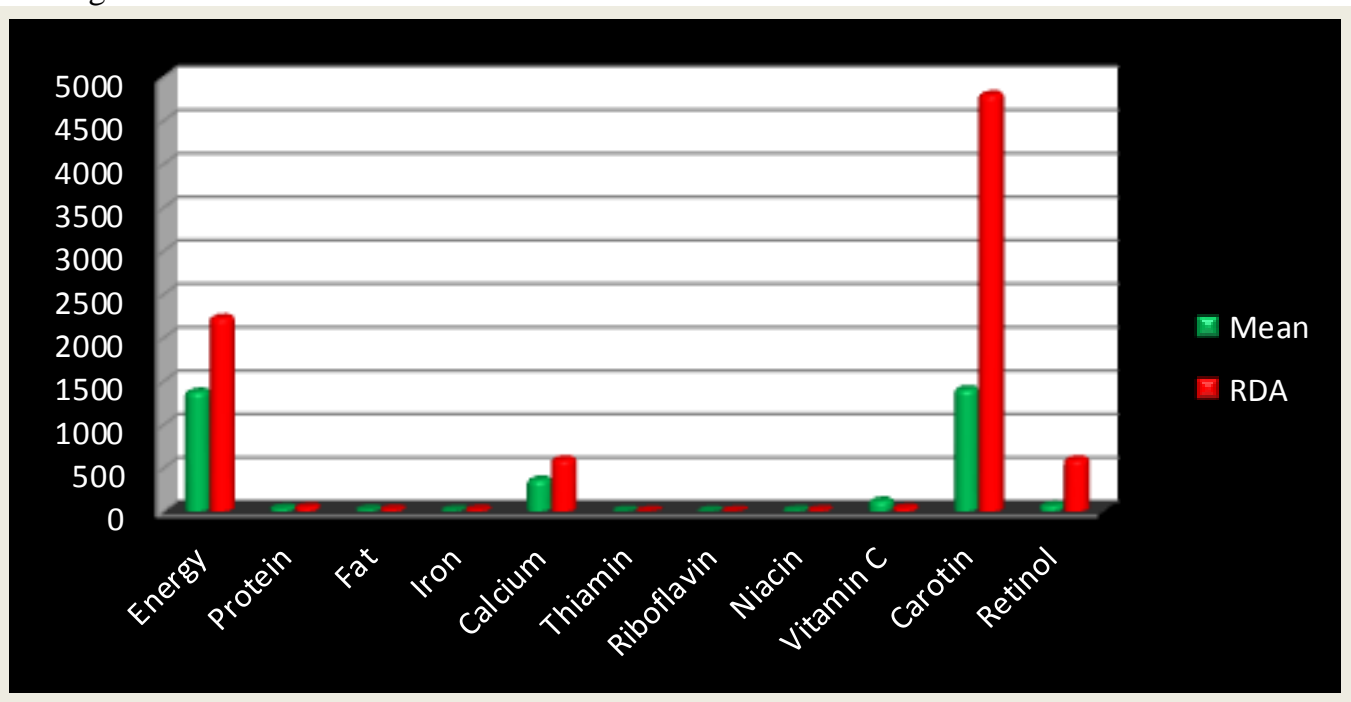

Figure 2 Nutrient intake of female subjects 


\section{Conclusions}

The present study entitled "Food and Nutrient Intakes of Patients with Colorectal Cancer in Calicut District of Kerala" was carried out with an objective to assess the nutritional status of colorectal cancer patients in Calicut District of Northern Kerala with reference to their food and nutrient intakes. The study had thrown light on the role of food, in cancer treatment, with more attention focusing on their dietary intakes. The findings of the study provided supporting evidences related to the inadequacy in the diets followed by the patients. Specifically this study showed that the intake of green leafy vegetables was low and it was less than 30 per cent of the RDA. Mean nutrient intake of the subjects after diagnosis showed that all the nutrients were found to be below the RDA levels except for vitamin $\mathrm{C}$. This high vitamin $\mathrm{C}$ might be attributed to the increased consumption of vitamin $\mathrm{C}$ rich fruits like oranges.

On the basis of the salient observations made in the study, following suggestions are made:

- Health status of colorectal cancer patients should be improved through better nutrition education.

- Motivate the patients to follow better nutritional practices which can prevent colorectal cancer.

- Inform the people about the importance of fruits, vegetables, green leafy vegetables etc. in cancer prevention and treatment.

\section{REFERENCES}

[1] M. Astin, T. Griffin, D. R. Neal, P. Rose, and W. Hamilton, The diagnostic value of symptoms for colorectal cancer in primary care: a systematic review, The British journal of Royal College of General Practice, 61(586), 2011, 231-243.

[2] M. L. Slattery, K.Curtin, R. K. Wolff, and J. S. Herrick, Diet, physical activity and body size associated with rectal tumor mutations and epigenetic changes, Cancer Causes Control, 21(8), 2010, 1237-1245.

[3] F. G. Campos, W. A. G. Logullo, D. R. Kiss, D. L. Waitzberg, A. Habr - Gama, and J. Gama- Rodriques, Diet and colorectal cancer: current evidence for aetiology and prevention, Nutricion Hospitalaria, 20(1), 2005, 18-25.

[4] M. Lipkin, B. Reddy, H. Newmark, and S. A. Lamprecht, Dietary factors in human colorectal cancer, Annual Review of Nutrition, $19,1999,545-86$.

[5] S. P. Nayak, M. P. Sasi, Sreejayan, and S. Mandal, A Case-control Study of Roles of Diet in Colorectal Carcinoma in a South Indian Population, Asian Pacific Journal of Cancer Prevention, 10, 2009, 565-568.

[6] R. M. Beegum, A Textbook of Foods, Nutrition \& Dietetics,(New Delhi :Sterling Publishers, 2008$) 327$.

[7] B. Srilakshmi, Dietetics, (New Delhi: New Age International publishers (PVT), 2005) 5.

[8] Indian Council of Medical Research, Nutrient requirements and recommended dietary allowances for Indians, (Hyderabad: National Institute of Nutrition, 2011) 12

[9] S. Capra, M. Ferjuson, and K. Ried, Cancer impact of nutrition intervention outcome-nutrition issues for patients, Nutrition, 17, 2001, 769-772.

[10] P. V. Bertuccio, Edefonti, and F. Bravi, Nutrient Dietary Patterns \& Gastric Cancer Risk in Italy, Journal of National Cancer Institute, 2009, 2882-2886.

[11] V. K. Ahluwalia, and M. Ahluwalia, Cancer Causes and Prevention, (New Delhi: Lotus press, 2005$) 143$. 